\title{
MEDICAL STUDENT FIELD STUDIES AND THE PARTNERS OF THE ALLIANCE PROGRAM
}

\author{
George Entwisle * and Josê Rodrigues Coura **
}

In 1968, the Department of Tropical Medicine of the Faculdade de Medicina, Universidade Federal Fluminense (U.F.F. , had an opportunity to participate with a North American medical school in a medical student field experience which deve:oped within the framework of the Partners of the Alliance program. In view of the interest of many Latin American departments of preventive and social medicine, in the development of affiliations with North American medical schools, and since the Partners of the Alliance Program is a novel approach for such affiliations, the implementation of this medical student field experience will be reviewed briefly.

The Partners of the Alliance Program developed out of recognition that the Alliance of Progress, which is a governmentto-government effort, did not provide adequate opportunities for individuals and groups in both the United States of America and Latin America to work together in self-help programs. In the Partners of the Alliance Program, Latin American countries are identified with sister or partner states in the U.S.A. For example, Ecuador is paired with Kentucky, and Mexico is paired with California. A large country may be paired with more than one state in North America. Different states in Brazil are paired with Wyoming, Virginia, Tennessee, Ohio, Pennsylvania, Missouri, New Jersey, Maine, Maryland, Indiana, Colora- do and Illinois. Partners of the Alliance Committees are formed in each of the partner states and these committees include individuals from labor and civic organizations, business, educacional and professional fields.

Estado do Rio is paired with state of Maryland and, during a visit of the Maryland Partners Committee to Rio, there was an oppcrtunity to explore the possibility of a professional and technical exchange with the University of Maryland. This led to communication with the medical school faculty at the University of Maryland and subsequently a visit to Estado do Rio by the chairman of the Department of Preventive Medicine at the University of Maryland. Early communication and subsequent discussions centered around an exchange program which would involve students and faculty of both medical schools spending time at the other school. A feasible first step in the development of such an exchange program was considered to be one where three medical students and a faculty member from the University of Maryland would spend the winter of 1968 in Niteroi, participating in a health survey of a well defined area of the city. The study was conducted jointly by Brazilian and American medical students, with supervision by the Department of Tropical Medicine and a faculty member from the Maryland medical school. The objectives

* Professor and Chairman, Department of Preventive Medicine, University of Maryland School of Medicine

* Professor and Chairman, Department of Tropical Medicine, Faculdade de Medicina, Universidade Federal Fluminense and Universidade Federal do Rio de Janeiro.

Submitted to publication on 19.6.70. 
for the summer's experience were limited, and included the determination of feasibility of this field experience despite limited funds, and the identification of health problems that could be pursued in subsequent studies. The specific project selected for the students was fairly simple and focused on the completion of a prepared ha.. alth questionnaire at a sample of householding the defined area. In addition, all household children under age five were tested for anemia and stool parasites, and physical measurements were obtained to extend the observation, reported from Peru, that severe nutritional problems in children were related to birth order. An immunization program for all children in the defined area was scheduled.

We consider this initial venture to have been successful despite some minor problems. The visiting medical students worked well with Brazilian medical, social work, and nursing students. The household survey was completed with a response rate of 94 percent and the collected data are useful in planning further studies. On the wards of the local hospitals, our visitors were able to see many infectious diseases which were new to them. These experiences, and the opportunity to live with Brazilian families, probably enchanced the expressed interest of these visiting medical students in future international health work.

Since other departmens of preventive medicine may wish to consider this arproach to the development of medical student field studies, the cost, sources of swy port, and other sources of information will be summarized briefly. The total cost of the summer field experience, exclusive of faculty salaries, was:

a. Round trip air fares: 3 medical students and 2 faculty members (University of Maryland) .. . . .

b. Fortuguese language lessons for visitors $\ldots \ldots \ldots \ldots \ldots \ldots \ldots$

Fellowship support for 3 North American medical students ....

d. Incidental expenses .........
Fellowship support for the visiting medical students was made available through the Maryland State Department of Health. The round trip airline tickets for the three medical students and one faculty member were provided by the National Association of the Partners of the Alliance,* a non-profit voluntary agency. The visitors had Portuguese lessons before leaving Maryland and the cost of these language lessons, the initial visit to Brazil by the Department Chairman, and some of the incidental expenses were paid from funds of the Department of Preventive Medicine at $\mathrm{Ma}$ ryland.

Funds for housing the visitors were not available, but soon after their arrival, each visiting medical student was invited into the home of a Brazilian family where he lived for the two month period of the visit.

The program was not continu $\alpha$ in the Winter of 1969 because travel funds for the visitors did not become available until late in the fall when there was not enough time for implementation of field studies In January 1970, two medical students and a faculty from the Faculdade de Medicina (U.F.F.) will be visiting the University of Maryland School of Medicine in Baltimore, Maryland. In July of 1970 , three medical students and the Chairman of the Department of $\mathrm{N}$. W. Preventive Medicine from the University of Maryland will be coming to Niteroi to continue field studies jointly with the Faculdade de Medicina.

Housing for the visiting teams will continue to be provided in the host country, and the Universidade Federal Fluminense will arrange for Portuguese lessons to be given $\mathrm{t}$ o the visiting medical students next July .

Medical school faculties in Latin America are aware that large amounts of money are available to North American medical schools for the support of research and special training programs. The federal government Department of Health, Education and Welfare of the U.S.A. provides most of the research and training grant

$\$ 8,893$ funds of departments of preventive medi-

* National Association of the Partners of the Alliance, $1518 \mathrm{~K}$ Street, N. W. Washington, D. C. 20005; Mr. Robert Lloyd Nelson, Director. 
cine at North American medical school: and certain federal restrictions on the expenditure of these funds preclude their use in developing an affiliation program of the kind we are describing. These restrictions are such that federal funds caniot be used to provide stipends to North American medicai students during overseas assignment, and the funds cannot be used to pay for international travel of these medical students. Thase restrictions require that other sources of financial support be available to implement an affiliation program. In the United States of America such funds must be sought from a private foundation or from some branch of the Federal Government other than Depar.tment of Health, Education and Welfare. Support for travei of two medical studen!s and a facuity membar from Brasil to Maryland in January of 1970 is being provided by the Agency for International Development of the United States of America. $A$. indicated earlier, expenditures for the vi... siting team in Júly and August 1968 were from funds of a private foundation, the Maryland State Department of Health, and non-federal funds of the Department of Preventive Medicine at Maryland.

The sources of support for this type of affiliation would therefore include the nadical schools and universities of the part- ner states, the Agency for International Development, the National Association of Partners of the Alliance, and possibly other foundations. Since very North American State has a department of health and since it is common for these state health depar.. ments to sponsor medical student feliowships, other states in Norti America may be willing to allocate such fellowship support, as Maryland did, for medical students working in Latin America. Hopefully, housing for visitors would be provided by the host country with the assistancs of the local Partners of the Alliance Committee.

Departments of preventive medicine seeking more information about the Partners of the Alliance Program or the activities of the National Assonation of the Partness of the Alliance could write these organization for more information.* Also available from the Partners office is a directory listing the members of the Partners Committees in each of the United States as well as the members of the corresponding Committess in Latin America. Another document which may be of value is a direstory of the chairmen of departments of preventive aedicine in North America. A copy of this directory may be obtained from the Association of Teachers of Preventive Medieine.*:

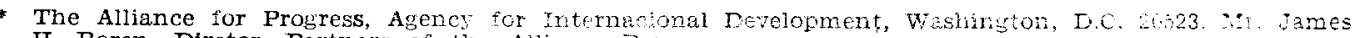
H. Boren, Diretor, Partners of the Alliance Prosrams.

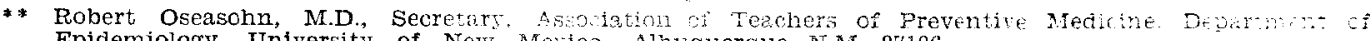
Epidemiology, University of New Mexico, Albuquercue, N.M. 87106. 